\title{
Science and the imagination in the age of reason
}

Robin Downie The University of Glasgow

\begin{abstract}
The eighteenth century is commonly thought of as the "age of reason", an age in which the imagination was not given a central role in the arts, far less in science.

But in Hume's attempts to account for our belief in a continuing external world he is forced into invoking the activity of the imagination. His views on the activity of the imagination greatly influenced Adam Smith, who adapted them to fashion a theory of the psychology of scientific discovery. In this theory the imagination is shown to be active in creating systematic explanations of the phenomena of nature, to the extent that Smith depicts the aim of scientific theory as that of satisfying the imagination. Smith's account of the logic of scientific theory can be defended even in contemporary philosophy of science. In particular, it can be maintained that all scientific theories are works of the imagination and that the concept of truth does not directly apply to them.

( $(\mathcal{M}$ Med Ethics: Medical Humanities 2001;27:58-63)
\end{abstract}

Keywords: Science; philosophy; imagination; Hume; Adam Smith

\section{Introduction}

There are many possible connections between science, including medical science, and the imagination. The obvious bridge between the two is science fiction, in which writers can suggest possible worlds or situations which scientists have yet to explore, or draw out the deeper moral and social implications of what scientists are suggesting. Again, writers or artists can present in imaginative terms what it might feel like to be on the inside of a clinical situation. Sometimes the more striking aspects of science-such as cosmology-can make an appeal to the imaginations of us all and inspire the feelings of awe and reverence celebrated by writers on the sublime. My concern in this paper, however, is not with any of the above links between science and the imagination. Rather I wish to explore the links in one particular historical period-the middle of the 18th century. Moreover, I shall concentrate on two important figures of that period-David Hume and, more especially, Adam Smith. I have chosen to discuss Adam Smith because his views on the role of the imagination in scientific discovery raise issues of continuing relevance to the present day.

The first half of the 18 th century is often thought of as "the age of reason". The standard view is that it was the age when the science of Newton began to grow from its 17 th century roots, and philosophy, either rationalist or empiricist, was based respectively on reason or on what could be observed by the senses. According to the standard view, during this period the role of imagination in science and philosophy, and indeed in art and literature, was limited, and it was not until the last decades of the century, when the philosophy of Kant had demonstrated the creative powers of the mind, that the central role of the imagination was appreciated. The 19th century was then thought to have developed Kant's approach, and the imagination was celebrated in many areas of human endeavour. So goes the standard account of the history of the imagination. In this paper I shall not mount a radical challenge to the standard view, but more modestly suggest that in the thought of at least two leading figures of the mid-eighteenth century an important role is ascribed to the imagination, especially in scientific discovery.

\section{Hume and the imagination}

Hume's assumptions about the mind and its materials were largely inherited from his empiricist predecessors and especially John Locke. Basically these views are that the mind's perceptions of the outside world take the form of impressions, rather as impressions can be imprinted on wax. We have no access to the world except through these impressions which are, by their very nature as impressions, irreducibly mental. Our awareness of the world is therefore an awareness of the mental. This starting point generates serious problems for Hume. Firstly, there is the problem of how we think when the mind is not receiving impressions, and secondly there is the the problem of how these "distinct perceptions", the impressions, become related to each other and agglomerated into the perceptual objects of the familiar world we know, which continues to exist when we are not presently observing it. In dealing with these problems he relies on a view he developed not from John Locke but from the moral philosophy of his predecessor Francis Hutcheson-namely that our belief in the continuing existence of material objects independent of us depends not on our senses or our reason but on our human natures. In particular, Hume invokes the imaginative power of human nature to explain both thought, when there are no impressions present to our consciousness, and also our belief in the continued existence of bodies when there are no immediate impressions. 
First of all, Hume uses the imagination to explain how we can think when there is no impression present to us. Suppose, like Wordsworth, that we have just visited a beautiful scene with daffodils. We later remember this scene in tranquillity. According to Hume "the idea of it flows in upon the mind in a forcible manner". ${ }^{1}$ This is memory-a vivid idea. Suppose now that we have not actually seen these daffodils but imagine them. According to Hume we still have a mental image, but whereas the memory image is forceful, "in the imagination the perception is faint and languid, and cannot without difficulty be preserved by the mind steady and uniform for any considerable time" ${ }^{1}$ In other words, the difference between memory and imagination is simply in the greater vivacity of the images of memory. Now, of course, Hume may be wrong in suggesting that ideas of the memory are always or typically more forceful than those of the imagination, but that point is not important for present purposes. The important point in this context is that the imagination is not restrained by the order or the form of the original impressions. The imagination can reassemble the impressions in any order and create satyrs and fauns at will. In other words, the imagination is free and by its means our thoughts can range where we wish and are not tied down like the images of memory to repeat the order in which the impressions were first received.

Moreover, there is another way in which the imagination can help us to think when impressions are not present to our consciousness. It can help in the formation of general and abstract ideas. The imagination enables us to form general and abstract ideas because it can fetch from past impressions all the ones relevant to a given general idea. For example, if we have had past impressions of a rose then the imagination enables us to form the general idea or concept of a rose. The more varied the past impressions the deeper our concept will be. Now we may use the image of a red rose to represent the concept, but if someone were to suggest that all roses are red then, if our past impressions have been sufficiently varied, immediately our imagination will bring to mind a yellow rose. Similarly, if we are told that all roses grow on bushes a metre high, then our imagination will call up the image of a climbing rose. Likewise, to turn to abstract ideas, one triangle (say, an isosceles triangle) can represent all triangles in our mind, but if someone were to suggest that all triangles have two equal sides then immediately the imagination would bring to mind a scalene triangle. This function of the imagination, to produce relevant individual images to assist abstract thought in the absence of present impressions, represents a great advance on Locke's account.

It is worth noting here, although it is not part of my main theme, that while the use of the imagination was appreciated by writers of the mid-18th century it was not regarded as a major feature of the best art or literature. This was because the idea of "imitation" was a dominant one, in both the graphic arts and in literature. Good art did not express the imaginative but rather reflected nature with order and decorum, "What oft was thought, but ne'er so well expressed". ${ }^{2}$ Writers and philosophers of the 19th century, who did stress the centrality of the imagination in art, were more influenced by the second function which Hume ascribed to the imagination, to which I shall now turn.

So far I have been discussing briefly Hume's account of the function of the imagination in enabling us to think when impressions of the world are not immediately present to our senses. The second main function which Hume ascribes to the imagination is that of filling in the gaps in our perceptions of the world. Hume uses the imagination to solve two sorts of problem which arise from his account of our perceptions of the external world. Both arise out of what we might call the "gappiness" of experience. For example, suppose we have an impression of the kitchen table at which we are working. We then cross to the sink to fill the kettle which we place on the cooker, and then we return and receive a second impression of the table. Now Hume thinks that impressions are what he calls "particular perishing existences", ${ }^{3}$ so our second impression of the table will be distinct from the first. Yet we say that it is the same table. What enables us to do that? That is Hume's first problem, and his answer is that our imaginations have a tendency to identify resembling perceptions. In other words, if you look at the table, look away and look back again you have had two numerically distinct perceptions but because they resemble each other the imagination fills the gap and postulates the existence of a table continuing across the perceptual gap.

He gives a similar answer to his second problem. In the terms of a modern example, if you put the kettle on and then answer the telephone the imagination attributes a coherence to the world so that you are not surprised that the kettle is boiling when you return. Hume makes the point that the imagination is active in going beyond the senses and building up for us the familiar world we perceive. This idea was to be taken up by Kant and turned into his transcendental philosophy. Moreover, as I hinted above, it was also taken up by writers such as Coleridge, who stressed the creative, the "shaping power" of the imagination in art. That story, however, does not concern me here; rather I shall first be concerned with the simpler story of the way in which Adam Smith took hold of Hume's ideas on the work of the imagination, especially Hume's account of the activity of the imagination in partly creating the world we perceive, and turned them into an account of creativity in science.

\section{Adam Smith and science}

Adam Smith's views on the function of the imagination in science are to be found in his History of Astronomy. Scholars are not clear on the exact date of this work. It shows extensive knowledge of science as well as the influence of Hume, and it was not published until some years after his death in 
1790 , edited by his scientific friends Joseph Black and James Hutton. Yet it is thought to be an early work, and it is possible that Smith intended it to form part of an extensive history of the arts and sciences. Its interest to contemporary readers lies not in the details of the account it gives of the history of astronomy-which have long been superseded by more up-to-date scholarship-but rather in the account it gives of the psychology of scientific discovery. The key is provided in the full title of the work: The Principles which lead and direct Philosophical Enquiries: illustrated by the History of Astronomy.

Before proceeding we should note that Smith, in common with other writers of the period from Newton to Hume, did not draw the distinctions which would now be drawn between philosophy and the natural sciences. They would equally be called "philosophy", although sometimes further distinctions were made between "natural philosophy" and "moral philosophy", or between the "natural sciences" and the "moral sciences". It is certainly clear from the context and the details of the argument that Smith is speaking of what we would regard as science rather than what we would regard as philosophy. What then is Smith's account of the role of the imagination in scientific discovery?

Smith notes that the imagination is often "indolent" in the sense that we become so familiar with some process that we do not raise questions about it. He takes the example of a skilled artisan, such as a brewer or a dyer. Artisans can bring about remarkable changes in their materials but, since they are familiar with the changes, see nothing remarkable in them. The artisan "cannot conceive what occasion there is for any connecting events to unite those appearances, which seem to him to succeed each other very naturally. It is their nature, he tells us, to follow one another in this order, and that accordingly they always do so". ${ }^{4}$ It is the role of the imagination to disturb this indolence, and it is the philosopher (scientist) whose imagination is especially active in causing this disturbance. Before proceeding further with an exposition of Smith we should note the similarity between what Smith is here saying and what Coleridge and Wordsworth were later to say in the preface to the Lyrical Ballads. ${ }^{5}$ Coleridge and Wordsworth saw the function of the poet as that of removing the film of familiarity which coats everyday objects and situations, and thus of making us more vividly aware of them. For Smith the scientist is more vividly aware of the natural world than we ordinarily are in everyday life. The scientist "who has spent his whole life in the study of the connecting principles of nature, will often feel an interval betwixt two objects, which, to more careless observers, seem very strictly conjoined". "Smith's scientist and Coleridge's and Wordsworth's romantic poet are alike, then, to the extent that each uses the imagination to give us new insights into the familiar natural world.

They are also alike in that the scientist, like the poet, finds a stimulus to the imagination from what Smith calls "sentiments". The sentiments in question are (for Smith) surprise, wonder, and admira- tion. Here is how Smith introduces the operation of these sentiments. He takes the case of something unexpected, such as unforeseen good or bad fortune. "We are at first surprised by the unexpectedness of the new appearance, and when that momentary emotion is over, we still wonder how it came to occur in that place". ${ }^{6}$ In other words, we feel surprise when we come across some event, object or group of objects which does not fit into the pattern we expect. The sentiment of surprise is followed by that of wonder.

What is "wonder"? $\mathrm{He}$ explains it as follows: "The stop which is thereby given [by surprise] to the career of the imagination, the difficulty it finds in passing along such disjointed objects, and the feeling of something like a gap or interval betwixt them, constitute the whole essence of this emotion [wonder]". " Not quite "the whole essence", because wonder also leads us to seek an explanation of the gaps, to provide links which will eliminate the sense of wonder by assigning the "disjointed objects" to a new ordering in which the imagination can find repose.

In more detail, the operation of wonder (which is really the most important of the sentiments which stimulate the imagination) can be summarised as follows. (I shall mainly use Smith's own words (Astronomy, section II). The mind takes pleasure in observing resemblances between different objects, and consequently in arranging them into classes, technically called genera and species. The greater our knowledge, the more divisions and subdivisions of genera and species. When something new turns up this generates wonder when we try to assign it to some familiar class. There is a second kind of wonder which is generated not only by individual objects but also by uncommon trains or successions of objects. The second kind of wonder is also generated by interruptions of customary succession with which the imagination is familiar. The imagination tries to fill the gaps in these interruptions, to enable it to "flow smoothly" along apparently disjointed events. Philosophers (ie scientists) who have spent their lives studying the connecting principles between objects will often note intervals between two objects which more careless observers will think are strictly conjoined. In sum, "Philosophy [science], therefore may be regarded as one of those arts which address themselves to the imagination...". So much for Smith's account of how the sentiment of wonder stimulates the imagination.

If we succeed in thus finding a coherent explanation then our appreciation of the events or objects is "heightened" and the third sentiment, of admiration, follows the wonder. Thus, a theory of astronomy may help us to admire the heavens through presenting the "theatre of nature" as a coherent "and therefore more magnificent spectacle". ${ }^{8}$ Note the aesthetic language used by Smith: "heightened" appreciation, "theatre of nature" and "magnificent spectacle". The three sentiments which stimulate the scientific imagination, then, are surprise, wonder, and admiration. 
In addition to the detailed account in Astronomy (section II) of how the sentiment of wonder provides a stimulus to the imagination, we can find scattered remarks which add to the general aesthetic picture which Smith provides of science. For example, he rejects the Baconian view of the scientific enterprise as an attempt to control nature. "Wonder, therefore, and not any expectation of advantage from its discoveries, is the first principle which prompts mankind to the study of Philosophy, of that science which pretends to lay open the concealed connections that unite the various appearances of nature; and they pursue this study for its own sake, as an original pleasure or good in itself, without regarding its tendency to procure them the means of many other pleasures". 9 This account of scientific discovery could easily be adapted to a romantic view of the pleasures of poetry. Astronomy (section IV) is the most scientific part of the work, and in this section he provides accounts of many systems of astronomy from the Greeks to Newton. But he never loses sight of his theme of the centrality of the imagination to science. For example, he explains how the introduction of the "Equalizing Circle" solved various technical problems in measurement. The "Equalizing Circle" was, in Smith's words, "invented" because the imagination was "confounded and embarrassed" by apparently irregular and inconstant motions of the planets. By postulating this circle and inviting us to survey the revolutions of the planets from this postulated central point the harmony and repose of the imagination was restored. "Nothing can more evidently show, how much the repose and tranquillity of the imagination is the ultimate end of philosophy, than the invention of this Equalizing Circle". ${ }^{10}$

Smith seems to think that it is systematic links which above all "soothe" the imagination, and he goes on to explain the nature of a system, and (with yet another aesthetic term) to tell us why some systems are to be preferred to others-namely, in terms of their simplicity.

"Systems in many respects resemble machines. A machine is a little system, created to perform, as well as to connect together, in reality, those different movements and effects which the artist [note Smith's use of 'artist'] has occasion for. A system is an imaginary machine invented to connect together in the fancy those different movements and effects which are already in reality performed. The machines that are first invented to perform any particular movement are always the most complex, and succeeding artists generally discover that, with fewer wheels, with fewer principles of motion, than had originally been employed, the same effects may more easily be produced."11

The aesthetic notion of the beauty of simplicity is further developed when he reviews the system of astronomy adopted by Copernicus.

"Neither did the beauty and simplicity of this system [adopted by Copernicus] alone recommend it to the imagination; the novelty and unexpectedness of that view of nature, which it opened to the fancy, excited more wonder and surprise than the strangest of those appearances, which it had been invented to render natural and familiar, and these sentiments still more endeared it. For, though it is the end of Philosophy [science], to allay that wonder, which either the unusual or seemingly disjointed appearances of nature excite, yet she never triumphs so much, as when, in order to connect together a few, in themselves, perhaps, inconsiderable objects, she has, if I may say so, created another constitution of things, more natural indeed, and such as the imagination can more easily attend to, but more new, more contrary to common opinion and expectation, than any of those appearances themselves." 12 Here we have yet another aesthetic criterion being employed in the assessment of a scientific theory-novelty. There can be no doubt that Smith would understand novelty to be an aesthetic characteristic since novelty was commonly seen as such in 18 th century aesthetics.

\section{Hume and Smith: discussion}

In discussing Smith's account of the role of the imagination in science we can be sure of one thing at the start-the influence of Hume's account of the imagination in creating the external world we all perceive. Smith does not mention Hume by name in his Astronomy, but he was very familiar with Hume's writings and admired them. As we have seen, for Hume the imagination is active in filling the gaps in our distinct impressions of the world and thus giving us the illusion of a constant and coherent world, and for Smith the imagination is active in filling the gaps in the customary successions which are necessary to provide us with mental repose and tranquillity. This idea of the activity of the imagination was to be taken up first by Kant, who developed it in the transcendental philosophy of The Critique of Pure Reason (1781), and then more generally it was adopted in various forms throughout the 19 th century. ${ }^{13}$ There is a line in Coleridge's Dejection: an Ode which expresses the function of the imagination in both the arts and science. Coleridge speaks of "My shaping spirit of Imagination". ${ }^{14}$ In the context of the poem it is clear that the "shaping spirit of imagination" is identified with "joy", which, as Coleridge uses the term, suggests excitement and a satisfaction that the experience is worth having for its own sake. As we have seen, Smith had given an account of the delight of the imagination in filling the gaps in a system to give tranquillity to the imagination. Coleridge's line condenses the point that in both science and art we understand the world through our imaginations.

Now, whereas we might agree with Coleridge (and Smith) about "the shaping spirit of imagination" in both science and art we might still want to know about the connection in Smith's account between the repose of the imagination and the facts of nature. To put the problem more bluntly, Smith takes the view that "the repose and tranquillity of the imagination is the ultimate end of Philosophy [science]", ${ }^{15}$ but many people would take the com- 
monsense view that the ultimate end of science is truth. What is the connection between the imagination and truth?

One possibility is suggested by Keats in a letter to Benjamin Bailey dated 22nd November, 1817. "I am certain of nothing but of the holiness of the Heart's affections and the truth of ImaginationWhat the imagination seizes as Beauty must be truth....The Imagination may be compared to Adam's dream-he awoke and found it truth". ${ }^{16}$ Keats must here be thinking of a particular kind of truth which poetry can offer; his view certainly does not apply to what Adam Smith was discussing, for in Smith what is thought to satisfy the imagination is a structured system introduced to explain gaps in our scientific knowledge of the world. Coleridge is nearer the mark when he speaks of the imagination as "shaping".

But does a systematic shaping, which gives repose to the imagination, necessarily give truth? This raises the question of the extent or the sense in which a scientific theory can be said to be true. The following must be taken as a simple statement of one of several possible views to be found in contemporary philosophy of science. We must first distinguish between the data-the observations and experiments in science-and the hypotheses which are introduced to explain the data and to give rise to predictions. The observations and predictions are open to empirical verification; they are repeatable or not and statements based on them can be true or false in a standard way. But the hypotheses belong to a different logical category. They are formulated as putative explanations and to enable us to ask more questions of nature.

It is clear from Smith's writings that, in common with other writers on science of the time, including Newton, he is aware of both these levels of science, and that he is really attributing two functions to the imagination. Firstly, there are gaps in the scientist's observations, or unusual and unexpected sequences of events, which cause surprise and lead to wonder. The imagination may be satisfied when further events are discovered which fill in the gaps or complete the sequences. But these further observations are testable and can be shown to be true or false. If they do not truly fill the gaps the imagination will remain uneasy. Verification and truth have clearly central roles here. But, secondly, when we turn to hypotheses we find products of the imagination which are neither true nor false. They are assessed, according to Smith, in terms of their systematic coherence, simplicity, novelty, and beauty or, in other words, by their power to soothe the imagination. Some general conclusions can be drawn from this.

In the unfolding of science since the 17th century it is possible to detect the increasing realisation that scientific theory is a conceptual system, a structure of hypotheses within which the more particular bear to the more general the relation of necessary consequence. To establish this necessary relation on a systematic basis is to constitute a theoretical explanation. It can be seen that there can never be any finality about a scientific theory, because it can never be shown that the particular facts or limited generalisations of facts which a given theory is constructed to explain could not equally follow from another theory. This was the great insight of Adam Smith. Yet even he, he admits, was tempted to see in Newton's principles a system which was established truth.

"And even we, while we have been endeavouring to represent all philosophical systems as mere inventions of the imagination, to connect together the otherwise disjointed and discordant phaenomena of nature, have insensibly been drawn in, to make use of language expressing the connecting principles of this one, as if they were the real chains which Nature makes use of to bind together her several operations" ${ }^{17}$ But, despite this temptation to see Newton's system as truth, Smith remains clear that it is an imaginative construction which for the time being explained the phenomena of nature, or "saved the appearances". Smith's point is surely a persuasive one: that while the imagination may lead scientists to devise systems, or connecting principles, from which testable inferences can be drawn, no imaginative construction of the mind can be used to set limits to the mind.

Kant developed this point and made it explicit in the preface to the second edition of his Critique of Pure Reason.${ }^{18}$ His point is that science must be seen as a creative activity, and not a mere dissection of nature. We must see scientfic theories as the creations of an active imagination attempting to make sense of the world, to explain the observed facts by showing how they can be deduced from a theory. This view of science, and the freedom of the scientific imagination to roam like that of the artist, has continued into the present century. Indeed, even one of Kant's assumptions-that space is necessarily Euclidean-has been disposed of by the highly imaginative non-Euclidean geometries developed in the earlier part of the 20 th century.

It was the failure to see that scientific theories are simply creations of the imagination which can never be definitively shown to be "true", but must constantly be under revision as new facts are observed, which gave rise to the crises of conscience in the 17th century over Galileo and in the 19th century over Darwin. These controversies show a misunderstanding of scientific theory. Scientific theories can give no support to believers or to atheists, to determinists or to libertarians. What they can do is to delight the imagination; but the scientific imagination, like its artistic counterpart, must continue to reach out towards new constructions.

Robin Downie is Professor of Moral Philosophy at the University of Glasgow.

\section{References}

1 Hume D. A treatise of human nature. Oxford: Clarendon Press, 1896: I.I.III.

2 Pope A. An essay on criticism. In: Grant D, ed. Poems of Alexander Pope. Harmondsworth: Penguin, 1950 3 See reference 1: I.IV.II. 
4 Smith A. The principles which lead and direct philosophical enquiries: illustrated by the history of astronomy. In: Wightman W, Bryce J eds. Essays on philosophical subjects [Glasgow edition] Oxford: Oxford University Press, 1980: II.11

5 Coleridge ST. Biographia literaria. London: Dent, 1949: ch 14

6 See reference 4: II.8.

7 See reference4: II.9.

See reference 4: II.12.

See reference 4 : III 5 .

See reference $4: 1 \mathrm{~V} .13$

11 See reference 4: 1V.19.
12 See reference $4: 1 \mathrm{~V} .33$.

13 Kant I. Critique of pure reason [translated by Kemp Smith N]. London: Macmillan, 1929.

14 Coleridge ST. Dejection: an ode. In: Gardner H, ed. The new Oxford book of English verse. Oxford: Clarendon Press, 1972: 546.

15 See reference 4: 1V.13.

16 Keats J. Letter to John Bailey. In: Forman MB, ed. The letters of Fohn Keats. Oxford: Oxford University Press, 1952: 67.

7 See reference 4: 1 V.76.

18 See reference 13: preface to 2 nd edition.

\section{News and notes}

\section{Association for Medical Humanities: Announcement of inaugural meeting}

The inaugural meeting of the proposed Association for Medical Humanities, described in more detail elsewhere in this issue (see page 104), will be held on Saturday 9th February 2002 at the University of Birmingham Medical School. The programme, which lasts from 1000 to 1630 , will incorporate the formal establishment of the association; it will also involve plenary and workshop discussions to consider research and teaching in medical humanities, and appropriate structures and tasks for the association.
All medical schools in the British Isles, and all universities in the British Isles with specific interests in research and teaching in the medical humanities, are expressly invited to participate.

Further details may be obtained from: $\mathrm{Mr}$ R G Arnott, Director, Centre for the History of Medicine, The Medical School, University of Birmingham, Birmingham B15 2TT, email: r.g.arnott@bham.ac.uk 